\title{
UNDERSTANDING THE REBOUND SURFACE HARDNESS OF CONCRETE
}

\author{
Katalin SZILÁGYI, Adorján BOROSNYÓI, István ZSIGOVICS \\ Department of Construction Materials and Engineering Geology, \\ Budapest University of Technology and Economics, Müegyetem rkp. 3, 1111 Budapest, Hungary
}

Received 25 Apr 2012; accepted 27 Aug 2012

\begin{abstract}
Surface hardness testing of materials can be considered as the oldest method to get information about strength related material properties. In recent decades the rebound hammer has been the most popular surface hardness testing device for concrete uniting the advantages of its predecessors. In the technical literature numerous proposals are available for simple, two-parameter regression analyses of rebound surface hardness vs. compressive strength relationship of concrete. The remarkable diversity of the proposed curves implies the need of the more than two-parameter regression techniques to reveal the most pronounced parameters governing hardness behaviour. The objectives of present experimental studies were to carry out dynamic and static hardness tests, Young's modulus and compressive strength tests on concrete specimens. From the development of the tested properties with time it can be concluded that the rebound hammers provide a hardness value for high strength concretes connected to the Young's modulus rather than the compressive strength. Present paper includes a parametric simulation and a parameter fitting of the verified phenomenological constitutive model of the authors which recognizes the w/c ratio as the main driver of the interrelated material properties and gives a realistic formulation for the time dependent behaviour of the rebound surface hardness of concrete.
\end{abstract}

Keywords: concrete, compressive strength, Young's modulus, non-destructive testing, surface hardness, rebound index.

\section{Introduction}

Surface hardness testing of materials is a long established idea for the estimation of mechanical properties. First appearance of hardness goes back to 1640 when Alonso Barba came with the proposal of file scratch testing of minerals (Barba 1640). The 10-mineral scratching hardness scale was developed later by Friedrich Mohs in its present form used worldwide in geology (Mohs 1812). The pioneering theoretical studies of Heinrich Hertz in the 1880 's on mathematical modelling of linear elastic contact has shifted the experimental hardness testing towards the indentation methods (Hertz 1881). The first static indentation hardness testing laboratory device was developed by Johan August Brinell and was introduced to the public at the Paris Exposition Universelle (Brinell 1901). As a further development, dynamic surface hardness testing devices also appeared (Durometer by Albert F. Shore 1911; Duroskop by Rational GmbH 1930). For the insitu testing of structural concrete the first surface hardness testing device was developed by Kurt Gaede in the form of a spring hammer (Gaede 1934). The method adopted the idea of the indentation hardness measurements. Next step of development for the concrete surface hardness testing spring hammers was the appearance of the rebound hammer designed by Ernst Schmidt
(1951). The schematic operating principle of the rebound hammer can be studied in Figure 1. The main aim of the rebound hammer was to provide the advantages of the easy handling of spring hammers together with the easy

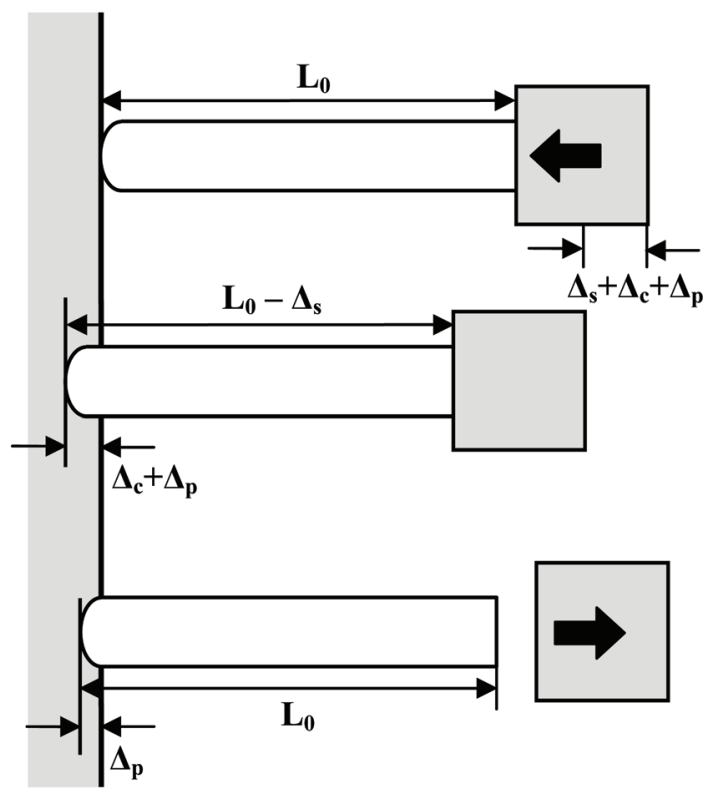

Fig. 1. Operating principle of the rebound hammer 
reading of the measured value of durometers. The measure of surface hardness is the rebound index rather than the ball penetration. Due to this development the surface hardness measurement became much easier since the rebound index can be read directly on the scale of the device and no measurements on the concrete surface are needed. The latest development of the concrete surface hardness testing spring hammers was finalized in 2007. Since then devices that can measure coefficient of restitution, are available as well (Proceq 2007).

Rebound surface hardness measurements are popular for in-situ testing of structural concrete due to the inexpensive testing devices and their relatively simple use.

Numerous publications are available in the technical literature concerning experimental results and analyses. Aim of rebound hammer tests is usually to find a relationship between surface hardness and compressive strength with an acceptable error. However, it can be found in some publications that the method is suitable only for assessing the uniformity of concrete.

\section{Rebound index vs. strength relationships}

The rebound index vs. strength relationship can be determined if experimental data are available. The usual practice is to consider the average values of the replicate compressive strength and rebound index results as one data pair at each strength level. The data pairs are presented using the rebound index as the independent variable (along the $\mathrm{X}$ axis) and the compressive strength as the dependent variable (along the $\mathrm{Y}$ axis). Regression analysis is performed as a conventional least-squares analysis on the data pairs to obtain the best-fit estimate for the strength relationship. The technical literature calls the attention that the boundary conditions of the conventional least-squares analysis are violated in the case of rebound index vs. strength relationships (Carino 1993); therefore, it is not recommended because the uncertainty in the strength relationship would be underestimated. It should also be added that both strength and hardness of concrete are results of further parameters (w/c ratio, degree of hydration, type of cement, type of aggregate, etc.), therefore, a two-parameter regression between hardness and strength may lead to completely misleading results and can hide the real driver of the relationship. In the technical literature numerous proposals are available for simple, two-parameter regression analyses of rebound surface hardness and compressive strength of concrete, regardless of the theoretical restrictions of mathematical statistics.

Composition of the proposed regression relationships can be summarized as follows (in which $f_{c m}$ is the estimated mean strength; $R$ is the rebound index; $a \ldots n$ are empirical values) (Table 1).

If one tries to survey the technical literature on the strength estimating proposals that are based on rebound
Table 1. Proposed regression function types for the rebound index vs. strength relationship

\begin{tabular}{ll}
\hline linear functions & $f_{c m}=\mathrm{a}+\mathrm{b} \cdot R$ \\
\hline power functions & $f_{c m}=\mathrm{a}+\mathrm{b} \cdot R^{\mathrm{c}}$ \\
\hline polynomial functions & $f_{c m}=\mathrm{a}+\mathrm{b} \cdot R+\mathrm{c} \cdot R^{2}+\ldots+\mathrm{n} \cdot R^{\mathrm{m}}$ \\
\hline exponential functions & $f_{c m}=\mathrm{a}+\mathrm{b} \cdot \mathrm{e}^{\mathrm{c} \cdot R}$ \\
\hline logarithm functions & $\log _{\mathrm{a}}\left(f_{c m}\right)=\mathrm{b}+\log _{\mathrm{a}}(R)$ \\
\hline nonlinear functions & $f_{c m}=\zeta(R)$ \\
\hline
\end{tabular}
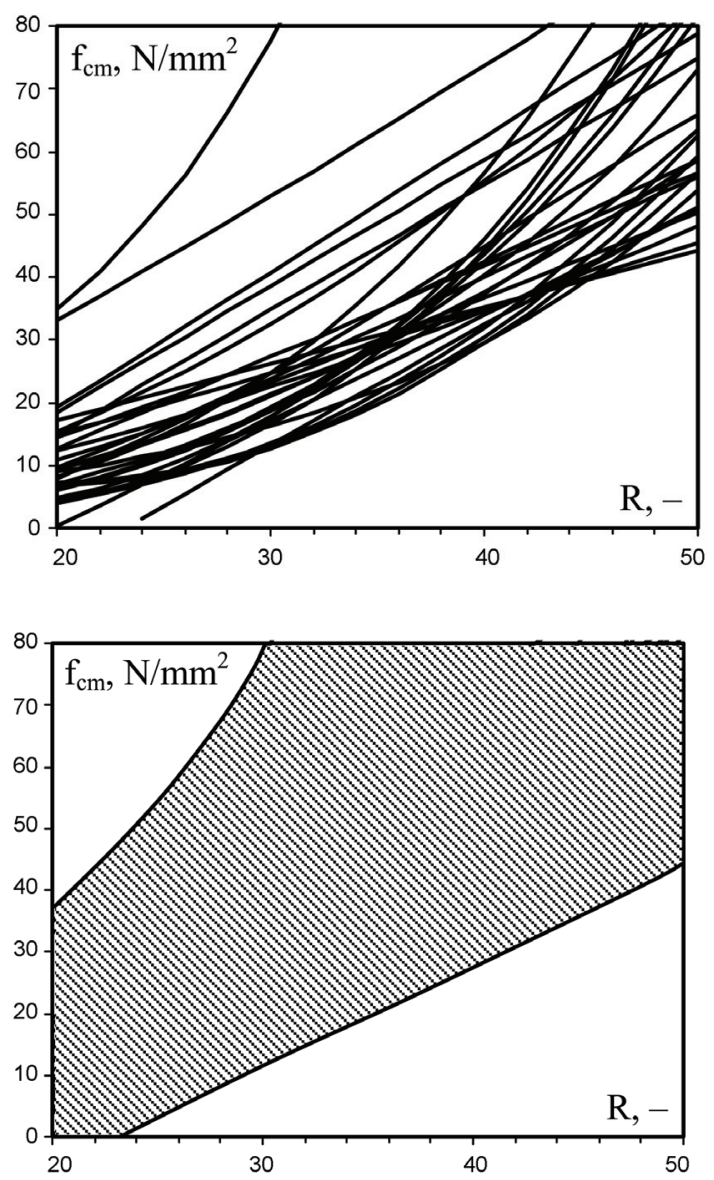

Fig. 2. Empirical curves for the rebound index vs. strength relationship and their overall range found in the technical literature (Szilágyi et al. 2011a)

surface hardness then several dozens of different relationships can be found; however, they are valid only within their limits of testing. None of the proposals can help the user to estimate the strength of concrete about which no information is available regarding the concrete composition. Figure 2 indicates 40 empirical curves as a demonstration based on a detailed literature survey (Szilágyi et al. 2011a).

Results summarized are valid for 28 to 365 days of age, conventional, normal-weight concretes under air dry moisture condition. It can be realized that the concrete strength can be estimated at certain rebound indexes by $\mathrm{a} \pm 40-60 \mathrm{~N} / \mathrm{mm}^{2}$ variation. 
Results clearly demonstrate that the validity of a proposal should be restricted to the testing conditions and the extension of the validity to different types of concretes or testing circumstances is impossible.

\section{First level of understanding: what do we measure?}

An experimental programme was completed on a wide range of compressive strength of normal weight concretes in Budapest University of Technology and Economics (BME), Department of Construction Materials and Engineering Geology, to study the surface hardness behaviour (Szilágyi et al. 2011b). Concrete was mixed from Danube sand and gravel using CEM I $42.5 \mathrm{~N}$ cement with w/c ratios of $0.40,0.50$ and 0.65 . Consistency of the tested concrete mixes was $500 \pm 20 \mathrm{~mm}$ flow. Design air content of the compacted fresh concrete was $1.0 \mathrm{~V} \%$. The specimens were cast into steel formworks and the compaction of concrete was carried out by a vibrating table. The specimens were stored under water for 7 days as curing. After 7 days the specimens were stored at laboratory condition (i.e. $20 \pm 3{ }^{\circ} \mathrm{C}$ temperature and $65 \pm 5 \%$ relative humidity). Tests were performed at the age of 3, 7, 14, 28, 56, 90 and 240 days. $150 \mathrm{~mm}$ cube specimens and $120 \times 120 \times 360 \mathrm{~mm}$ prism specimens were prepared for the experiments.

Surface hardness tests were carried out by Schmidt rebound hammers of L-type and N-type as well as with a Wolpert Leeb hardness tester with D-type impact device. The hardness tester devices has the same method of testing, i.e. an impact mass is accelerated by a spring toward the surface of the test object and impinges on it at a defined kinetic energy.

The masses of the used impact bodies were $380 \mathrm{~g}$ for the N-type Schmidt rebound hammer, $125 \mathrm{~g}$ for the L-type Schmidt rebound hammer, and $5.5 \mathrm{~g}$ for the Wolpert Leeb hardness tester. Altogether twenty individual rebound hammer test readings were recorded with the Schmidt rebound hammers used in horizontal direction on two parallel vertical sides of the $150 \mathrm{~mm}$ cube specimens restrained into a hydraulic compressive strength tester just before the compressive strength tests were carried out. Leeb scleroscope tests were carried out on the $120 \times 120 \times 360 \mathrm{~mm}$ prism specimens right after the completion of the Young's modulus measurements. Altogether 120 Leeb hardness readings were taken on the moulded side surfaces of each specimen.

Due to the adequate restraining action on the $150 \mathrm{~mm}$ cube specimens that were tested in present experiments with the Schmidt rebound hammers the within test standard deviation and the within test coefficient of variation became $\mathrm{s}_{\mathrm{R}}=2.3$ and $\mathrm{V}_{\mathrm{R}}=6.3 \%$, respectively, so the measurements can be considered to be rather accurate. Due to the unusually high number of the Leeb hardness measurement repetitions in present experiments the Leeb hardness values can also be considered to be available rather accurately.
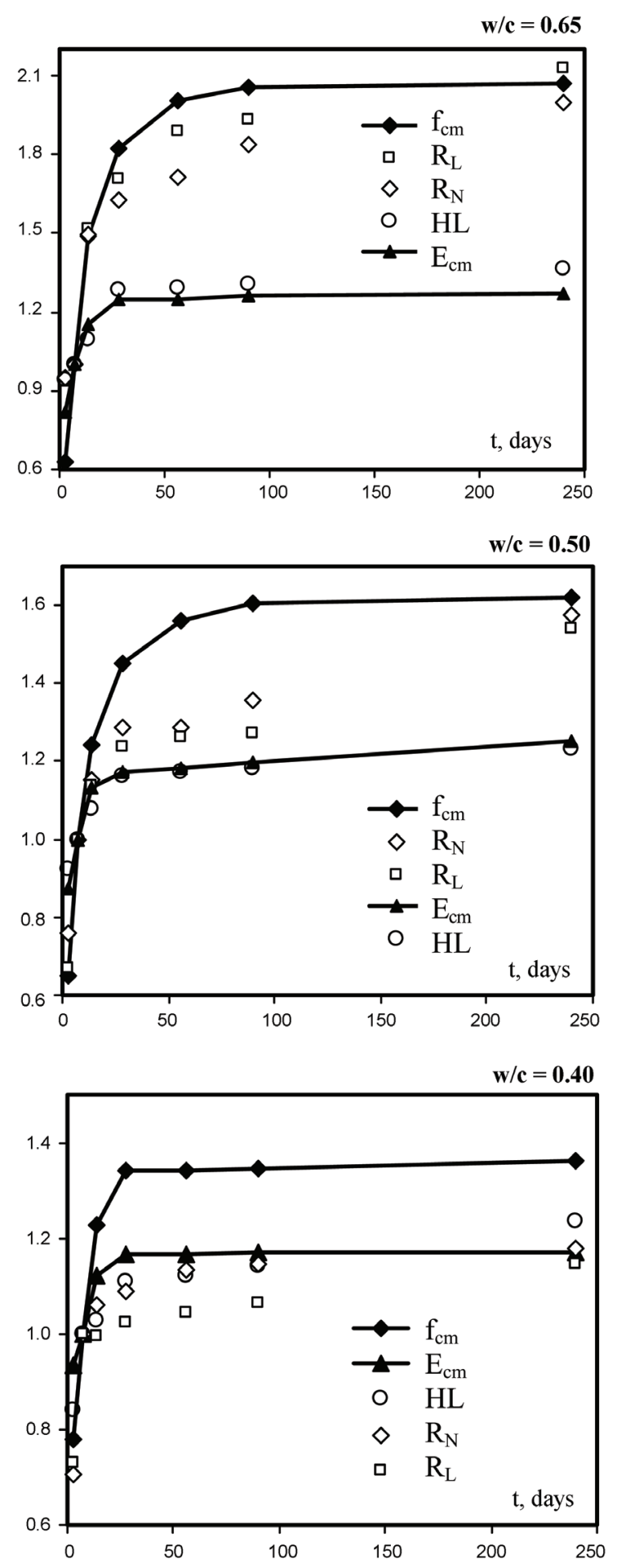

Fig. 3. Relative values of the tested parameters in the function of time

In Figure 3 the relative values (referring to the values obtained at the age of 7 days) of all tested parameters are represented over time scale.

Very low impact energy is introduced to the tested surface in the case of the Leeb hardness measurements and the material response mostly governed by the elastic properties 
of the tested material. Indeed, it can be realized in the graphical representation that the development of Leeb hardness values in time coincides exactly with the development of Young's modulus of concrete in time, on a wide range of compressive strength, and independently of the applied w/c ratio or age at testing.

The Schmidt rebound hammers apply much higher impact energy (both the L-type and the N-type devices) than the Wolpert Leeb hardness tester, therefore, the material response was found to be inelastic in a much more pronounced way; strongly depending on the actual strength and stiffness of the concrete.

The results demonstrate that the impact energy of the Schmidt rebound hammers can result considerable plastic deformations in the case of high w/c ratio (i.e. low concrete compressive strength). It can be realized in Figure 3(a) that the developments of $R_{L}$ and $R_{N}$ rebound indexes in time both coincide exactly with the development of compressive strength of concrete in time, independently of the age at testing.

The results also reveal that the impact energy of the Schmidt rebound hammers can result a predominantly elastic material response in the case of low $\mathrm{w} / \mathrm{c}$ ratio (i.e.
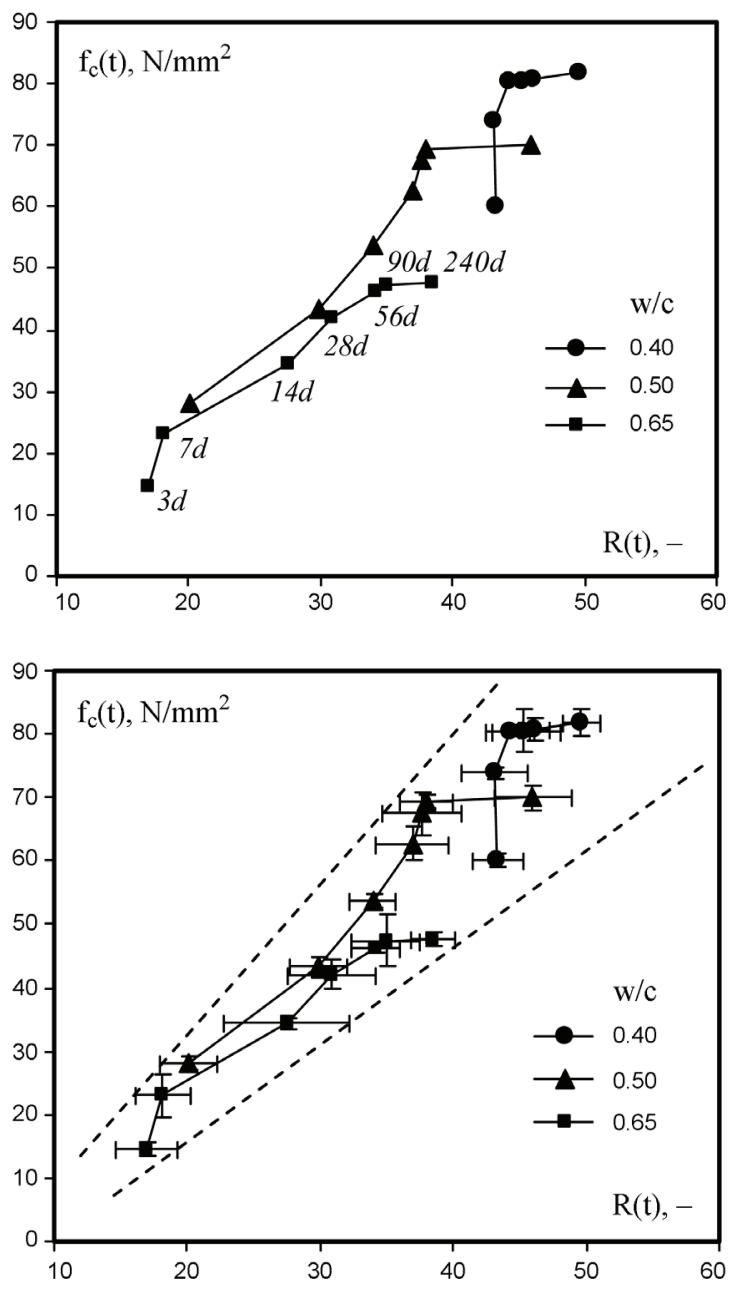

Fig. 4. Compressive strength of concrete in the function of the rebound index high concrete compressive strength). It can be realized in Figure 3(c) that the developments of $R_{L}$ and $R_{N}$ rebound indexes in time both coincide rather well with the development of Young's modulus of concrete in time, independently of the age at testing.

For the medium strength concretes an intermediate behaviour can be studied in Figure 3(b).

As a further representation, the $R_{L}$ rebound indexes are given in Figure 4(a) separated by the w/c ratios. The data points represent the average measured values for each testing age of the specimens that are indicated in the figure. Data points corresponding to the same $\mathrm{w} / \mathrm{c}$ ratio are connected with lines. To see the scatter of the measured results and a possible misleading heteroscedastic impression, Figure 4(b) introduces standard deviations for both rebound indexes and compressive strengths. The reader can realize that despite the acceptable scatter in the results an apparently heteroscedastic data group may be generated if one carelessly represents the measured data points alone, without taking the importance of $\mathrm{w} / \mathrm{c}$ ratios into account.

The shape of the resulted series of lines clearly demonstrate that the rebound index vs. compressive strength relationships cannot be generalized to the level of a twoparameter regression data field and a three- or more parameter analysis is needed for the modelling.

\section{Second level of understanding: what is the main driving force?}

The primary factor that governs the characteristics of cementitious materials is porosity. A simplified parameter to describe the porosity of concrete is the $\mathrm{w} / \mathrm{c}$ ratio. For practical purposes it can be accepted that the $\mathrm{w} / \mathrm{c}$ ratio determines the capillary porosity of a properly compacted concrete at any degree of hydration (Mindess, Young 1981; Neville 1995). As a consequence, strength and related properties of concrete can be accepted to depend primarily on the w/c ratio (Feret 1892; Abrams 1918). Surface hardness of concrete is also considerably influenced by the $\mathrm{w} / \mathrm{c}$ ratio in addition to the modulus of elasticity of the aggregate particles (which is usually considered to be constant in time). Hydration of clinker minerals in the hardened cement paste makes the per se heterogeneous concrete to be a material having time dependent properties. Based on the above assumptions, a phenomenological constitutive model was formulated for the surface hardness of concrete as a time dependent material property (Szilágyi et al. 2011a).

The phenomenological constitutive model recognizes the $\mathrm{w} / \mathrm{c}$ ratio as the main driver of the interrelated material properties that can describe time dependency of the rebound index vs. strength relationship. Origination of the model is based on the time dependent development of the capillary pore system of the hardened cement paste in concretes and the $w / c$ ratio is used as a practical simplification.

The model covers the empirical material laws of the relationship between $\mathrm{w} / \mathrm{c}$ ratio and compressive strength at the age of 28 days; the development of compressive 
strength in time; the relationship between compressive strength and the rebound index at the age of 28 days; the development of carbonation depth of concrete in time; the influence of carbonation depth of concrete on the rebound index.

The model was constructed to apply twelve empirical constants and was found to be capable to describe experimental results on surface rebound hardness of concrete. The model was verified on 864 test specimens of a seven parameter experimental test that clearly confirmed its application possibilities (Szilágyi et al. 2011a).

In the followings a parametric simulation for the model is given. Empirical formulations are selected from the technical literature for the generator functions of the model.

For the w/c ratio vs. compressive strength of concrete at the age of 28 days (for cement type of CEM I $42.5 \mathrm{~N}$ ) the empirical formula of Ujhelyi is selected due to the assumptions made by Ujhelyi and Popovics (2006):

$$
\boldsymbol{f}_{c, 28}=406 \cdot \exp \left\langle-3.30 \cdot(\boldsymbol{w} / \boldsymbol{c})^{0.63}\right\rangle\left[\mathrm{N} / \mathrm{mm}^{2}\right] .
$$

Development of the compressive strength in time depends on the type of cement and the w/c ratio (Wood 1991). Models available usually neglect the influence of the w/c ratio. For the parametric simulation the proposal of the CEB-FIP Model Code 1990 (CEB 1993) is selected for the development of compressive strength in time, neglecting the influence of the $\mathrm{w} / \mathrm{c}$ ratio:

$$
\boldsymbol{f}_{c}(t) / \boldsymbol{f}_{c, 28}=\exp \left\langle 0.25 \cdot\left(1-(28 / \boldsymbol{t})^{0.50}\right)\right\rangle .
$$

Rebound index vs. compressive strength relationships at the age of 28 days are generally non-linear. For the parametric simulation the proposal of Proceq SA (manufacturer of the Schmidt rebound hammers) (Proceq 2003) is selected for the rebound index vs. compressive strength relationships at the age of 28 days:

$$
\boldsymbol{f}_{c, 28}=3.07 \times 10^{-2} \cdot \boldsymbol{R}_{28}^{1.952}\left[\mathrm{~N} / \mathrm{mm}^{2}\right] .
$$

The hardened cement paste in concrete reacts chemically with carbon dioxide $\left(\mathrm{CO}_{2}\right)$. The amount of $\mathrm{CO}_{2}$ present in the atmosphere is sufficient to cause considerable reaction with the hardened cement paste over a long period of time. The chemical reaction is referred as carbonation, whenever the hydrated lime content of the hardened cement paste turns to limestone by the chemical reaction with $\mathrm{CO}_{2}$. Rate of carbonation depends on the relative humidity and was found to be greatest around $50 \% \mathrm{RH}$ (Neville 1995). Development of the depth of carbonation in concrete with time can be described reasonably well by models based on Fick's law of diffusion. For the parametric simulation the model of Papadakis et al. (1992) is selected for the carbonation depth of concrete. Its generalized form for the development of the carbonation depth in time is:

$$
\begin{aligned}
\boldsymbol{x}_{\boldsymbol{c}}= & \psi 0.35 \rho_{c} \frac{\boldsymbol{w} / \boldsymbol{c}-0.30}{1+\frac{\rho_{c}}{1000} w / c} f(\boldsymbol{R H}) . \\
& .\left(\left(1+\frac{\rho_{c}}{1000} w / c+\frac{\rho_{c}}{\rho_{a}} a / c\right) C_{C O_{2}} \frac{23.8}{44} 10^{-6} \boldsymbol{t}\right)^{0.50}[\mathrm{~mm}] .
\end{aligned}
$$

In Eqn (4) the parameter $f(\boldsymbol{R} \boldsymbol{H})$ can be taken according to the results of Matoušek (1977). If one accepts $f(65 \% \mathrm{RH})=0.45, \mathrm{C}_{\mathrm{CO}_{2}}=800 \mathrm{mg} / \mathrm{m}^{3}, \rho_{c}=3150 \mathrm{~kg} / \mathrm{m}^{3}$ and $\rho_{a}=2650 \mathrm{~kg} / \mathrm{m}^{3}$ then Eqn (4) can be simplified and rearranged and can be rewritten as:

$$
\boldsymbol{x}_{\boldsymbol{c}}=(0.50 \cdot(\boldsymbol{w} / \boldsymbol{c})-0.14) \cdot \sqrt{\boldsymbol{t}}[\mathrm{mm}] .
$$

Limits of use of application for Eqn (5) are $0.35<\boldsymbol{w} / \boldsymbol{c}<$ 0.65 and $4.50<\boldsymbol{a} / \boldsymbol{c}<6.50$. It means that cement content $\mathrm{c}=290 \mathrm{~kg} / \mathrm{m}^{3}$ to $420 \mathrm{~kg} / \mathrm{m}^{3}$ is to be assumed. For different relative humidity $(\mathrm{RH} \neq 65 \%)$ and $\mathrm{CO}_{2}$ concentrations Eqn (4) applies.

Surface hardness of concrete can be considerably changed by carbonation (Kim et al. 2009). Therefore, the influence of carbonation should be taken into account in the evaluation of rebound surface hardness tests. For the parametric simulation the proposal of the Chinese Standard $\mathrm{JGJ} / \mathrm{T} 23-2001$ is selected for the influence of carbonation depth on rebound index (JGJ 2001):

$$
\boldsymbol{R}(t) / \boldsymbol{R}_{28}=\frac{1}{1-0.067 \cdot \boldsymbol{x}_{c}^{1.0}} .
$$

The limit of use to apply Eqn (6) is $\boldsymbol{x}_{\boldsymbol{c}}<6.0 \mathrm{~mm}$.

A result of the present parametric simulation can be studied for five different w/c ratios in Figure 5. For one point on the series of the curves (indicated with dashed lines in Fig. 5) as an example the following details are given.

Starting value for water-cement ratio is $w / c=0.50$ and the age of concrete is $t=180$ days.

Based on formulae covered by Eqn (1) to (6) the numerical results can be calculated as follows:

By Eqn (1):

$f_{c, 28}=406 \cdot \exp \left\langle-3.30 \cdot 0.50^{0.63}\right\rangle=48.13 \mathrm{~N} / \mathrm{mm}^{2}$.

By Eqn (2):

$\boldsymbol{f}_{c}(180)=48.13 \cdot \exp \left\langle 0.25 \cdot\left(1-(28 / 180)^{0.50}\right\rangle=\right.$ $56.0 \mathrm{~N} / \mathrm{mm}^{2}$.

By Eqn (3):

$\boldsymbol{R}_{28}=5.96 \cdot 48.13^{0.512}=43.35$.

By Eqn (5):

$\boldsymbol{x}_{c} 180=(0.50 \cdot 0.50-0.14) \cdot \sqrt{180}=1.48 \mathrm{~mm}$.

By Eqn (6):

$\boldsymbol{R} 180=43.35 /(1-0.067 \cdot 1.48)=48.11$.

It can be realized that the model gives a realistic formulation for the time dependent behaviour of the rebound surface hardness of concrete. 


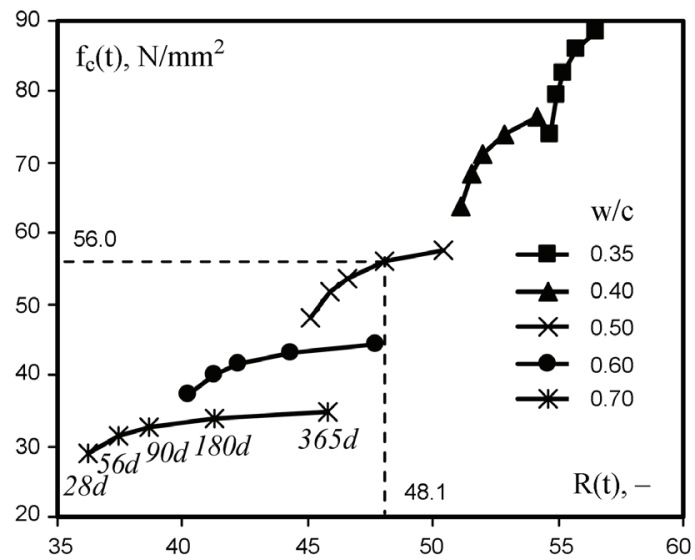

Fig. 5. Parametric simulation to the model

It can be clearly observed that the consideration of the data points as one group of data would not be acceptable; however, an appropriate selection of the parameters can generate a transparent and reliable series of curves that follow the real material response.

Figure 6 demonstrates the practical application of the model for the data summarized earlier in Figure 4. In the representation only those average data points are covered which correspond to 14-28-56-90-240 days of age at testing, because the test specimens were stored under water for 7 days, therefore, the carbonation was possible only when the specimens contacted the air during storing them at laboratory conditions. The curve fitting resulted the following empirical responses instead of Eqns (1) to (6):

$$
\begin{gathered}
\boldsymbol{f}_{c, 28}=225 \cdot \exp \left\langle-2.60 \cdot(\boldsymbol{w} / \boldsymbol{c})^{1.0}\right\rangle\left[\mathrm{N} / \mathrm{mm}^{2}\right] \\
\boldsymbol{f}_{c}(t) / \boldsymbol{f}_{c, 28}=\exp \left\langle 0.075 \cdot\left(1-(28 / \boldsymbol{t})^{1.0}\right)\right\rangle \\
\boldsymbol{f}_{c, 28}=11.04 \times 10^{-2} \cdot \boldsymbol{R}_{28}^{1.739}\left[\mathrm{~N} / \mathrm{mm}^{2}\right] \\
\boldsymbol{x}_{c}=(1.32 \cdot(\boldsymbol{w} / \boldsymbol{c})-0.40) \cdot \sqrt{\boldsymbol{t}-7}[\mathrm{~mm}] \\
\boldsymbol{R}(t) / \boldsymbol{R}_{28}=\frac{1}{1-n \cdot \boldsymbol{x}_{c}^{N}}
\end{gathered}
$$

where:

$$
\begin{gathered}
n=3.68(\boldsymbol{w} / \boldsymbol{c})^{5.07} \\
N=0.025(\boldsymbol{w} / \boldsymbol{c})^{-4.73} .
\end{gathered}
$$

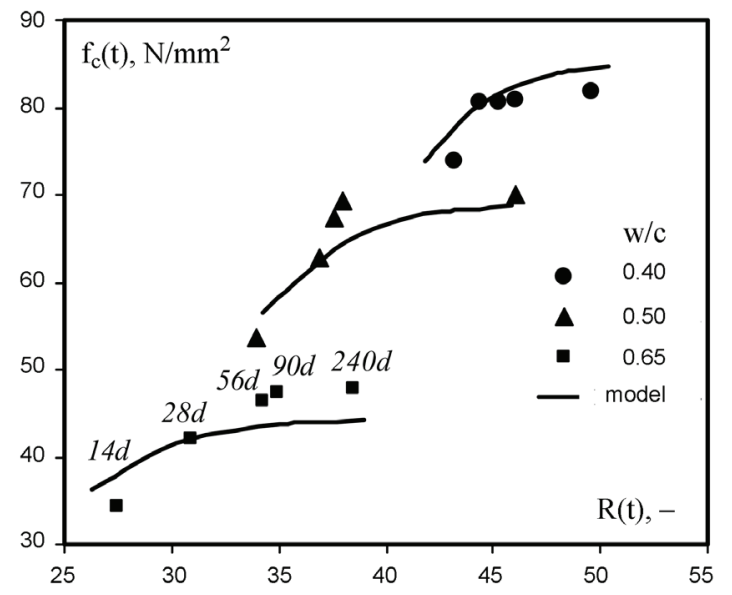

Fig. 6. Experimental results together with the parameter fitted model

\section{Discussion}

The experimental results demonstrated that the rebound index is a material property which is sensitive to the impact energy and the strength and stiffness of concrete tested. As a conclusion it can be noted that the Schmidt rebound hammers apparently provide rebound index that could be correlated to the compressive strength if the w/c ratio is high, thus the strength estimation is theoretically possible for relatively low strength concretes. On the other hand, for high strength concretes the Schmidt rebound hammers apparently provide rebound index that can be correlated to the Young's modulus of concrete, thus the strength estimation is of concern. The development of Young's modulus in time is considerably different from that of the compressive strength. As an example the simplifying formulae of the CEB-FIP Model Code 1990 are illustrated in Figure 7 for the development of strength and Young's modulus of concrete (CEB 1993).

According to the CEB-FIP Model Code 1990 an empirical power function between strength and Young's modulus can be taken into account with a power of 0.3 that can be put into the exponential formula considering time dependency of the properties.

Users should consider that Schmidt rebound hammers provide rebound index connected to the Young's modulus for high strength concretes and the Young's modulus could not predict compressive strength for mature concrete.

The composition of the introduced phenomenological model made the hidden governing parameters of the relationship between hardness and strength visible. Beyond strength and related properties the surface hardness of concrete was also found to be governed by the $\mathrm{w} / \mathrm{c}$ ratio. It was also confirmed that the excessive carbonation of low strength concretes has a considerable influence on the measured rebound index.

The graphical representation of the relationship between surface hardness and strength provided by the model is a series of curves which initial tangents are increasing with decreasing $\mathrm{w} / \mathrm{c}$ ratio. 


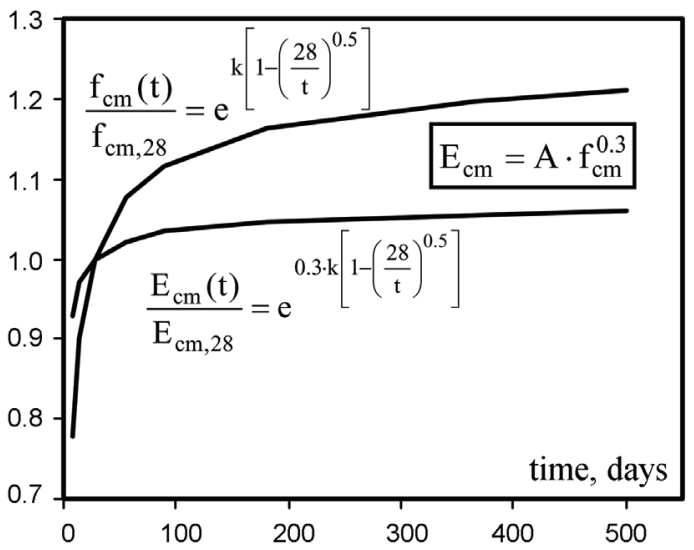

Fig. 7. Development of strength and Young's modulus of concrete in time (CEB 1993)

The rebound surface hardness behaviour of concrete can be understood based on the model, if curves at extreme positions are studied. The curve of a very low strength concrete tends to be an almost constant function (with very small tangent), in turn, a high strength concrete results a function with an almost infinite tangent.

The relationship with a small tangent would indicate increasing hardness with limited increase of strength in time. A very steep relationship related to the high strength concrete shows strength increment while no increase of hardness can be observed. This latter relationship implies again that the strength estimation of high strength concrete by the rebound hammer is of concern. This observation highlights similar findings regarding the time dependent results of the high strength concrete as was shown earlier.

To explain the change in the tangents of the curves according to the w/c ratio needs further research and analyses, as well as the twelve empirical constants should be fine-tuned to describe the realistic rebound surface hardness behaviour. However, it can be postulated at this point that the impact energy could be fitted to a range of one or two strength classes to ensure a necessary amount of inelastic energy absorption under the tip of the testing device. A curve of an intermediate tangent would indicate a proportional increase of strength with rebound surface hardness implying a possible strength estimation.

Indeed, the spring accelerated hammer mass of the original design rebound hammers was adjusted to provide adequate impact energy to result inelastic deformation in the tested concrete of which strength was much lower at the time of its development than the strength of concretes nowadays used in concrete construction.

\section{Conclusions}

Rebound surface hardness measurements are popular for in-situ testing of structural concrete due to the inexpensive testing devices and their relatively simple use.

Aim of rebound hammer tests is usually to find a relationship between surface hardness and compressive strength with an acceptable error.
As both strength and hardness of concrete are results of several parameters (w/c ratio, degree of hydration, type of cement, type of aggregate, etc.), a twoparameter regression between hardness and strength may lead to completely misleading results and can hide the real driver of the relationship.

The numerous proposals found in the technical literature cannot help the user to estimate the strength of concrete about which no information is available regarding the concrete composition.

A rigorous experimental analysis was carried out to examine the hardness behaviour of concrete. Dynamic and static hardness testing methods were studied on a wide range of compressive strength and the results were compared to Young's modulus and compressive strength measurements. Results demonstrated that the rebound hammers could provide a hardness value that can be correlated to the compressive strength of concrete only if the compressive strength is relatively low. It was confirmed for high strength concretes that the Schmidt rebound hammers provide a hardness value that can be correlated to the Young's modulus of concrete rather than the compressive strength.

With the formulation of a phenomenological constitutive model it can be clearly demonstrated that the rebound index vs. compressive strength relationships cannot be generalized to the level of a two-parameter regression data field and a three- or more parameter analysis is needed for the modelling.

The transparency of the model, thus the resulted series of curves indicate that the main driver of the time dependency of the rebound index vs. strength relationship is the development of the capillary pore system due to the hydration of cement.

Based on a parametric simulation it can be realized that the model gives realistic formulation for the time dependent behaviour of the rebound surface hardness of concrete.

Both experimental results and model analyses imply that more reliable strength estimation could be accomplished if the impact energy could be tuned to produce sufficient inelastic deformation of the concrete that needs further future research.

\section{Acknowledgements}

The work reported in the paper has been developed in the framework of the project "Talent care and cultivation in the scientific workshops of BME" supported by the grant TÁMOP-4.2.2.B-10/1-2010-0009. The authors gratefully acknowledge the support of the Jedlik Ányos PhD Candidate Scholarship supported by the National Excellence Program TÁMOP 4.2.4. A/1-11-1-2012-0001 - Elaborating and Operating an Inland Student and Researcher Personal Support System national program.

\section{References}

Abrams, D. A. 1918. Effect of time of mixing on the strength and wear of concrete, ACI Journal Proceedings 14(6): 22-92.

Barba, A. A. 1640. Arte de los metales [The art of metals]. Lima: Reprint. 278 p. 
Brinell, J. A. 1901. Mémoire sur les épreuves à bille en acier [Steel ball test report], in Communications presentés devant le congrés international des méthodes d'essai des matériaux de construction. Paris: Ministère du commerce, 83-94.

Carino, N. J. 1993. Statistical methods to evaluate in-place test results, in Liu, T. C.; Hoff, G.C. (Eds.). Proc. of the New Concrete Technology: Robert E. Philleo Symposium, ACI SP-141. American Concrete Institute, Farmington Hills, Michigan, 39-64.

CEB. 1993. CEB-FIP Model Code 1990 - Design Code, CEB Bulletin d'Information No. 213/214. London: Thomas Telford. $437 \mathrm{p}$.

Feret, R. 1892. Sur la compacité des mortiers hydrauliques [The compaction of hydraulic mortars], Annales des Ponts et Chaussees 7(4): 5-164.

Gaede, K. 1934. Ein neues Verfahren zur Festigkeitsprüfung des Betons im Bauwerk [A new method of strength testing of concrete in structures], Bauingenieur 35-36(15): 356-357.

Hertz, H. 1881. Über die Berührung fester elastischer Körper [About the contact of elastic solid bodies], Journal für die reine und angewandte Mathematik 92(2): 156-171.

JGJ. 2001. Technical specification for inspection of concrete compressive strength by rebound method. The People's Republic of China industry standard JGJ/T23-2001. Beijing: People's Republic of China Ministry of Construction. $32 \mathrm{p}$.

Kim, J. K.; Kim, C. Y.; Yi, S. T.; Lee, Y. 2009. Effect of carbonation on the rebound number and compressive strength of concrete, Cement and Concrete Composites 31(2): 139-44. http://dx.doi.org/10.1016/j.cemconcomp.2008.10.001

Matoušek, M. 1977. Působení vybraných atmosférických činitelù na stavebni konstrukce [Effects of some environmental factors on structures]. PhD Thesis. Technical University of Brno, Brno.

Mindess, S.; Young, J. F. 1981. Concrete. New Jersey: Prentice Hall. 671 p.

Mohs, F. 1812. Versuch einer Elementar-Methode zur Naturhistorischen Bestimmung und Erkennung von Fossilien
[Attempt of an elementary method to determine and indentify the fossils with a natural historical aspect]. Vienna: Gamesinaschen Buhhandlung. 128 p.

Neville, A. M. 1995. Properties of concrete. Harlow: Pearson Education. 844 p.

Papadakis, V. G.; Fardis, M. N.; Vayenas, C. G. 1992. Hydration and carbonation of pozzolanic cements, ACI Materials Journal 89(2): 119-130.

Proceq SA. 2003. Concrete Test Hammer N/NR, L/LR and DIGI SCHMIDT ND/LD - Rebound Measurement and Carbonation. Schwerzenbach: Proceq SA. 4 p.

Proceq SA. 2007. Silver Schmidt Operating Instructions. Schwerzenbach: Proceq SA. 48 p.

Rational, 1930. Duroskop Härteprüfer [Duroskop hardness tester]. Berlin Wilmersdorf: Rational GmbH. 2 p.

Schmidt, E. 1951. Versuche mit dem neuen Beton Prüfhammer zur Qualitätsbestimmung des Betons [Quality control of concrete by rebound hammer testing], Schweizer Archiv für angewandte Wissenschaft und Technik 17(5): 139-143.

Shore, A. T. 1911. Property of hardness in metals and materials, ASTM Proceedings 11(1): 733-739.

Szilágyi, K.; Borosnyói, A.; Zsigovics, I. 2011a. Rebound surface hardness of concrete: introduction of an empirical constitutive model, Construction and Building Materials 25(5): 2480-2487. http://dx.doi.org/10.1016/j.conbuildmat.2010.11.070

Szilágyi, K.; Borosnyói, A.; Dobó K. 2011b. Static indentation hardness testing of concrete: a long established method revived, Épitöanyag 63(1-2): 2-8. http://dx.doi.org/10.14382/epitoanyag-jsbcm.2011.1

Ujhelyi, J.; Popovics, S. 2006. A betonszilárdság és a víz-cement tényező közötti összefüggés megbízhatóságának javítása [Improvements in accuracy of the relationship between concrete strength and water-cement ratio], Vasbetonépités 8(1): 2-9.

Wood, S. 1991. Evaluation of the long-term properties of concrete, ACI Materials Journal 88(6): 630-643.

Katalin SZILÁGYI. He is a Civil Engineer (MSc), she was born in 1981, PhD candidate at the Department of Construction Materials and Engineering Geology, Budapest University of Technology and Economics. Research interests include diagnostics of concrete structures, non-destructive testing of concrete, concrete technology, shrinkage compensation of concretes.

Adorján BOROSNYÓI. He is a Civil Engineer (MSc), he was born in 1974, PhD, Associate Professor at the Department of Construction Materials and Engineering Geology, Budapest University of Technology and Economics. Research interests include application of non-metallic (FRP) reinforcements for concrete structures, bond in concrete, non-destructive testing of concrete.

István ZSIGOVICS. He is a Civil Engineer (MSc), he was born in 1949, PhD, Senior Lecturer at the Department of Construction Materials and Engineering Geology, Budapest University of Technology and Economics. Research interests include concrete technology, self-compacting concretes, diagnostics of concrete structures, non-destructive testing of concrete. 